\title{
Effect of Cholecystokinin and the Octapeptide of Cholecystokinin on the Feline Sphincter of Oddi and Gallbladder
}

\author{
MECHANISMS OF ACTION
}

\author{
J. Behar and P. Biancani, Department of Medicine, Rhode Island Hospital, \\ and Brown University, Providence, Rhode Island 02902, and \\ Department of Medicine, Veterans Administration Hospital, and Yale University \\ School of Medicine, West Haven, Connecticut 06510
}

A B S T R A C T We studied the effect of cholecystokinin (CCK) and the octapeptide of cholecystokinin (OP-CCK) on the feline gallbladder and sphincter of Oddi. Both CCK caused a dose-dependent gallbladder contraction and sphincter of Oddi relaxation. The halfmaximal responses of the sphincter of Oddi were 6 $\mathrm{ng} / \mathrm{kg}$ for OP-CCK and 0.15 Ivy-dog U/kg for CCK, which were lower than those of the gallbladder with 28 $\mathrm{ng} / \mathrm{kg}$ and $0.32 \mathrm{Ivy}-\mathrm{dog} \mathrm{U} / \mathrm{kg}$, respectively. The effect of OP-CCK on the gallbladder was partially blocked by tetrodotoxin $(P<0.02)$, hexamethonium alone $(P$ $<0.05)$, or a combination of hexamethonium and atropine $(P<0.01)$. The gallbladder response to CCK was not blocked by either atropine alone $(P<0.60)$ or adrenergic antagonists $(P>0.40)$. The sphincter of Oddi response to OP-CCK was blocked by tetrodotoxin $(P<0.001)$ but it was not blocked by cholinergic $(P<0.20)$ or adrenergic antagonists $(P<0.60)$. After complete denervation with tetrodotoxin, OP-CCK caused sphincter of Oddi contraction. These findings indicate that there are two excitatory receptors for CCK in the gallbladder, one at the cholinergic neurons and the other at the level of the gallbladder muscle. There are also two receptors for CCK in the sphincter of Oddi, one that is inhibitory, and present at the noncholinergic, nonadrenergic neurons, and the other, excitatory, at the circular muscle.

Address reprint requests to Jose Behar, M. D., Rhode Island Hospital, Providence, R. I.

Received for publication 18 December 1.979 and in revised form 1 August 1980.

\section{INTRODUCTION}

Cholecystokinin $(\mathrm{CCK})^{1}$ causes contraction of the gallbladder in man and experimental animals (1-3). In vitro studies have shown that this CCK effect results from direct hormonal action on gallbladder muscle (4, $5)$. It has been proposed that this action of $\mathrm{CCK}$ on the gallbladder is physiological (6). The effect of CCK on the sphincter of Oddi ( $\mathrm{SO})$, however, is controversial. While most studies have shown that CCK relaxes the SO (7-9), one has demonstrated SO contraction (10). Moreover, the mechanism of action of CCK on the SO has not been conclusively elucidated $(11,12)$.

The present studies were designed to determine, in vivo, the mechanism of action of CCK on the gallbladder, the CCK effect on the SO, and its mechanism of action on the SO.

\section{METHODS}

72 adult cats of either sex weighing $2-5 \mathrm{~kg}$ were studied. The animals were anesthetized with intramuscular Ketamine hydrochloride (30 mg/kg body wt) and maintained with small doses of $5-15 \mathrm{mg} / \mathrm{kg}$ as needed. They were studied in the supine position with a constant slow intravenous infusion of Ringer's solution with 5\% dextrose. Respiration was assisted and controlled with a ventilator (Harvard Apparatus Company, Inc., model N-607, S. Natick, Mass.) through a tracheostomy tube. Arterial blood pressure was

\footnotetext{
${ }^{1}$ Abbreviations used in this paper: CCK, cholecystokinin; $\mathrm{D}_{50}$, dose that causes half-maximal response; LES, lower esophageal sphincter; OP-CCK, octapeptide of cholecystokinin; SO, sphincter of Oddi; TTX, tetradotoxin.
} 
continuously monitored through a cannula placed in the femoral artery.

After a midline abdominal incision the gallbladder and biliary tree were identified. The cystic duct was isolated and cannulated with a catheter with an o.d. of $1.57 \mathrm{~mm}$, preserving its neural and blood supply. The integrity of the innervation of the gallbladder was tested by stimulating both ends of the cervical vagus and the splanchnic nerves. The gallbladder responded with contraction to each stimulation (13). After the gallbladder had been emptied, $3 \mathrm{ml}$ of normal saline was introduced. The cannula, filled with saline, was tied in the cystic duct using the purse-string technique to keep it in position and to avoid any leaks. Pressures were measured with a Statham pressure transducer (Gould-Statham Instruments, Inc., Hato Rey, Puerto Rico). The volume of $3 \mathrm{ml}$ was used because: (a) preliminary studies had shown that the mean fasting gallbladder volume in 12 animals was $3 \mathrm{ml}$ of bile, and (b) maximal gallbladder response to a maximal dose of OPCCK $(100 \mathrm{ng} / \mathrm{kg})$ was observed with this gallbladder volume. A pressure increment of $1.5 \pm 0.3 \mathrm{~mm} \mathrm{Hg}$ was observed when the gallbladder volume was $1 \mathrm{ml}$; when $2 \mathrm{ml}$ of saline were introduced, the increment was $1.9 \pm 0.5 \mathrm{~mm} \mathrm{Hg}$; with $3 \mathrm{ml}$ of saline, its response was $2.4 \pm 0.6 \mathrm{~mm} \mathrm{Hg}$; finally, with $4 \mathrm{ml}$ of saline, its response was $2.2 \pm 0.8 \mathrm{~mm} \mathrm{Hg}$. Gallbladder pressure was usually stable, but if any decline in pressure was observed, the gallbladder was emptied, and the same volume of normal saline was again introduced. This manometric method was capable of detecting accurately and reproducibly gallbladder contraction with bethanechol and relaxation with isoproterenol.

The SO pressures were measured using a modification of a previously reported method (14). A constantly perfused (0.3 $\mathrm{ml} / \mathrm{min})$, open-tipped, large catheter $(o . d .=1.57 \mathrm{~mm})$ was used. This catheter was placed in the common bile duct, advanced until resistance was encountered, and then withdrawn $1 \mathrm{~mm}$. At this point, it was anchored with a tight loop of suture silk, using the purse-string technique. The catheter was large enough to occupy almost the entire lumen of the common bile duct, and the tight loop prevented retrograde flow. Pressures thus recorded were reflections of the SO resistance to flow.

To validate this manometric method, the following preliminary studies were performed: $(a)$ Simultaneous pressure measurements of the SO and second portion of the duodenum showed that the SO pressures were $15-20 \mathrm{~mm} \mathrm{Hg}$ higher than duodenal pressures; SO phasic contractions were frequent and almost always independent in time from those of the duodenum. (b) Placement of a side-opening catheter in the common bile duct showed neither spontaneous nor pharmacologically induced contractions. The common bile duct did not respond to drugs, such as bethanechol and morphine, that caused SO contraction nor to drugs, such as OP-CCK and isoproterenol, that caused relaxation. (c) The SO pressure profile was also studied with a constantly perfused $(0.3 \mathrm{ml} / \mathrm{min})$ small catheter (o.d. $=0.51 \mathrm{~mm}$ ) with a side opening. This probe was introduced into the common bile duct and through the SO into the duodenum. Pressures were recorded in the duodenum and then gradually withdrawn in 1-mm steps. After the SO pressure profile was determined, the side opening was placed at the point of maximal sphincter pressure, where experiments with neural and pharmacological stimulation were performed. This method revealed that a similar SO behavior is observed with end-opening and side-opening catheters: $(a)$ There were high resting pressures with superimposed phasic contractions. Basal SO pressures were $27.5 \pm 3.4 \mathrm{~mm} \mathrm{Hg}(6$ experiments) using the catheter with side-openings, compared with $17.4 \pm 1.5 \mathrm{~mm} \mathrm{Hg}$ (24 experiments) when the open-tipped catheter was used. (b) Relaxation was the response to OP-CCK and isoproterenol, and contraction was the response to bethanechol and morphine. Thus, these preliminary studies show that SO response to pharmacological agonists was qualitatively similar with both manometric techniques.

All experiments with CCK were performed after bilateral cervical vagotomy. Electrical stimulation of the peripheral end of the vagus nerve was carried out by attaching an Ealing subminiature electrode (Ealing Corp., S. Natick, Mass.) to the nerve. The parameters of stimulation were $10 \mathrm{~Hz}, 10 \mathrm{~V}$, and pulses of $5 \mathrm{~ms}$ duration.

Gastrointestinal hormones and drugs, with the exception of tetrodotoxin (TTX), were given intravenously in bolus doses over a $30-\mathrm{s}$ period. TTX $(12-36 \mu \mathrm{g} / \mathrm{kg})$ was given in a slow infusion over a 20-30-min period. The pharmacological agents used were: synthetic OP-CCK, 0.5 to $200 \mathrm{ng} / \mathrm{kg}$ (Squibb Research, E. R. Squibb \& Sons, Inc., Princeton, N. J.); natural CCK (20\% pure), 0.03 to 2 Ivy-dog U/kg (Karolinska Institute, Stockholm, Sweden); TTX, 12-36 $\mu \mathrm{g} / \mathrm{kg}$ (Calbiochem-Behring Corp., San Diego, Calif.); atropine sulfate, $30 \mu \mathrm{g} / \mathrm{kg}$ (Eli Lilly and Company, Indianapolis, Ind.); hexamethonium hydrochloride, 20-40 mg/kg (City Chemical Corp., New York); phentolamine, 1-1.5 mg/kg (Ciba Pharmaceutical Company, Seymour, Ind.); propranolol, 1.5-2.0 mg/kg (Ayerst Laboratories, New York); morphine sulfate, $50 \mu \mathrm{g} / \mathrm{kg}$ (Wyeth Laboratories, Philadelphia, Pa.); bethanechol, 20-40 $\mu \mathrm{g} / \mathrm{kg}$ (Merck Sharp \& Dohme, Montreal, Canada); phenylephrine, $50 \mu \mathrm{g} / \mathrm{kg}$ (Robinson Laboratory Inc., San Francisco, Calif.); isoproterenol, $4 \mu \mathrm{g} / \mathrm{kg}$ (Whinthrop Laboratories, New York); nicotine, $100 \mu \mathrm{g} / \mathrm{kg}$ (Eastman Kodak Co., Rochester, N. Y.). Each pharmacological antagonist was used in a sufficient dose to block the dose of its agonist that produced a maximal effect on the SO and gallbladder.

Tonic gallbladder and SO pressures were measured as mean endexpiratory pressures over a 5 -min period immediately before and $30 \mathrm{~min}$ after the administration of a pharmacological antagonist. SO phasic contractions were measured as mean amplitude of the contractions above tonic pressures over a 5-min period immediately before and $30 \mathrm{~min}$ after the administration of the pharmacological antagonist. The effect of short-acting pharmacological agonists and gastrointestinal hormones was determined as the peak or nadir of pressures observed within a 10 -min period after their administration.

The paired and unpaired Student's $t$ tests were used for statistical analysis.

\section{RESULTS}

\section{Effect of CCK and OP-CCK on the gallbladder and $\mathrm{SO}$}

Basal gallbladder pressures were stable and only influenced by respiratory excursions (Fig. 1). The SO exhibited a steady, tonic contraction with superimposed spontaneous phasic contractions of variable rates and amplitude. These phasic contractions varied greatly from animal to animal but were relatively constant in each individual animal. These phasic contractions were brief and of greater amplitude than the respiratory excursions. Both CCK and OP-CCK caused simultaneous gallbladder contraction and SO relaxation. The gallbladder contraction induced by CCK or OP-CCK was characterized by a rapid increase 


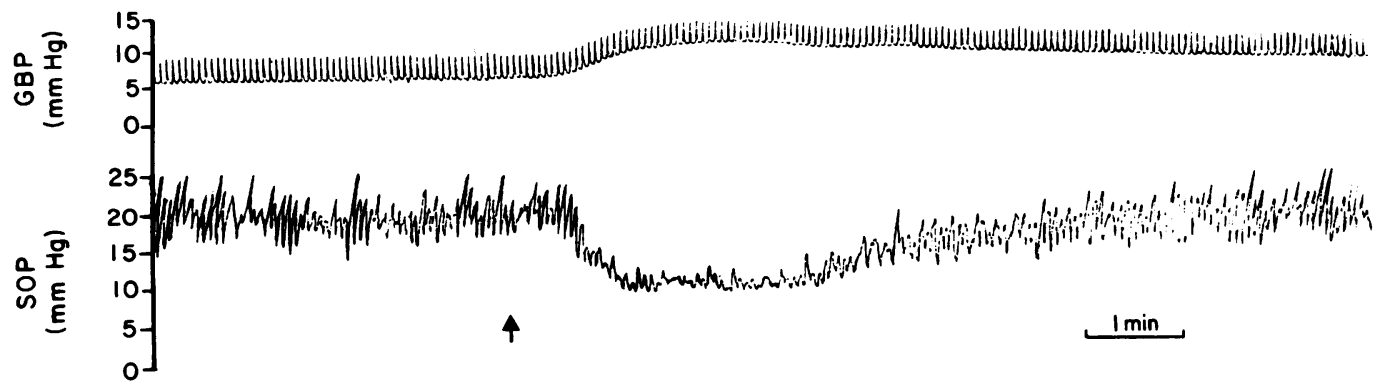

FIGURE 1 Tracing illustrates the effect of OP-CCK (100 ng/kg) on gallbladder (GPB) (upper panel) and SO pressures (SOP) (lower panel). Arrows indicate the timing of OP-CCK administration.

in pressure that quickly reached its peak and declined gradually. Both cholecystokinins abolished SO phasic contraction in addition to decreasing tonic pressures. The mean onset of action of both types of CCK was similar (29 s), but the mean duration of the action of CCK (23.4 min) was longer than that of OP-CCK (12.9 $\min )$.

Dose-response studies. A dose-dependent gallbladder contraction and SO relaxation (Figs. 2 and 3 ) were observed with increasing doses of CCK $(0.03-2.0$ Ivy-dog clinical U) and of OP-CCK $(0.5-200 \mathrm{ng} / \mathrm{kg})$ randomly administered. The maximal response occurred at a dose of 1 Ivy-dog clinical U/kg of CCK and of $100 \mathrm{ng} / \mathrm{kg}$ of OP-CCK for both the gallbladder and the SO. The dose that caused half-maximal response $\left(D_{50}\right)$ was calculated from the dose-response curves (Figs. 2 and 3). The $D_{50}$ for CCK and OP-CCK was lower for the SO than for the gallbladder. The $\mathrm{D}_{50}$ for the $\mathrm{SO}$ was 0.15 Ivy-dog clinical U/ $\mathrm{kg}$ for CCK and $6 \mathrm{ng} / \mathrm{kg}$ for OP-CCK. The $D_{50}$ for the gallbladder was 0.45 Ivy-dog clinical $\mathrm{U} / \mathrm{kg}$ for CCK and $28 \mathrm{ng} / \mathrm{kg}$ for OP-CCK. Because, on a weight basis, 1 Ivy-dog clinical $U$ is equal to $402 \mathrm{ng}$ of active peptide of CCK, OP-CCK is 10 times more potent than the natural cholecystokinin in the SO and 6.4 times more potent in the gallbladder.

\section{Pharmacological Analysis}

Effect of cholinergic antagonists. Table I shows that atropine did not change basal gallbladder pressures, nor did it antagonize the gallbladder-induced contraction by a maximal dose of OP-CCK $(100 \mathrm{ng} / \mathrm{kg})$. Gallbladder pressures after CCK administration increased by $2.3 \pm 0.4 \mathrm{~mm} \mathrm{Hg}$ before, and by $1.9 \pm 0.3 \mathrm{~mm}$ $\mathrm{Hg}$ after addition of atropine $(P<0.60)$. Similar results were observed when dose-response studies with OPCCK (1-200 $\mathrm{ng} / \mathrm{kg}$ ) were carried out before and after addition of atropine $(P>0.05$, Fig. 4). Hexamethonium, however, caused a slight gallbladder relaxation (Table I), decreasing basal pressures from $9.9 \pm 1.2$ to $8.7 \pm 1.2$ $\mathrm{mm} \mathrm{Hg}(P<0.001)$, and partially blocked the action of OP-CCK by reducing the gallbladder pressure increments from $1.7 \pm 0.2$ to $1.4 \pm 0.2 \mathrm{~mm} \mathrm{Hg}(P<0.05)$. Combined hexamethonium and atropine produced a further reduction in basal gallbladder pressures as well as in the gallbladder-pressure increment induced by OP-CCK (Table I). The combination of these two antagonists decreased gallbladder contraction resulting from CCK from $2.5 \pm 0.5$ to $1.1 \pm 0.2 \mathrm{~mm} \mathrm{Hg}(P<0.01)$. Likewise, these two cholinergic antagonists reduced gallbladder contraction in response doses of OP-CCK from $1-200 \mathrm{ng} / \mathrm{kg}(P<0.01$, Fig. 4).

To investigate the ability of hexamethonium, and combined atropine and hexamethonium to partially block the action of OP-CCK on the gallbladder, studies were carried out with nicotine before and after atropine was added and with atropine and hexamethonium combined. A maximal dose of nicotine $(100 \mu \mathrm{g} / \mathrm{kg})$ increased gallbladder pressures in six experiments by $2.0 \pm 0.5 \mathrm{~mm} \mathrm{Hg}$. Administering atropine at doses that blocked a maximal dose of bethanechol $(40 \mu \mathrm{g} / \mathrm{kg}) \mathrm{did}$ not completely antagonize the nicotine effect on the

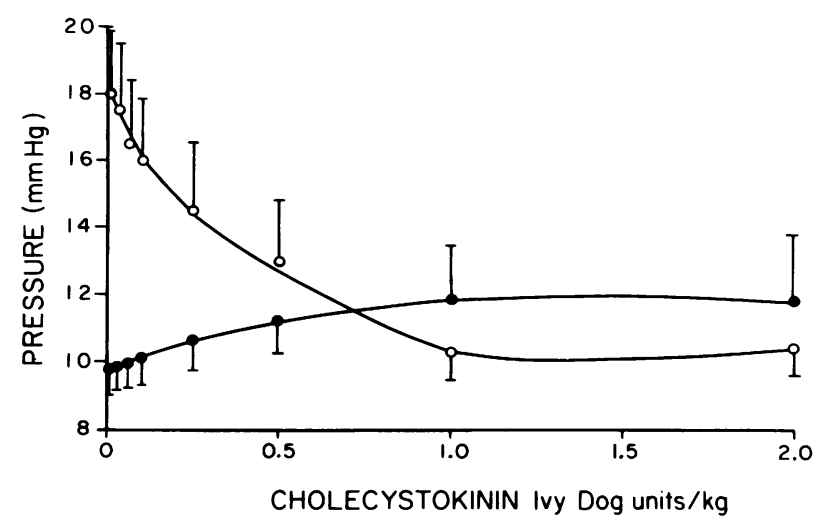

Figure 2 Dose-response studies of CCK (0.03-2 Ivy-dog $\mathrm{U} / \mathrm{kg}$ ) on tonic gallbladder $(\Theta)$ and SO (O) pressures. Values are means $\pm S E$ of four experiments. 


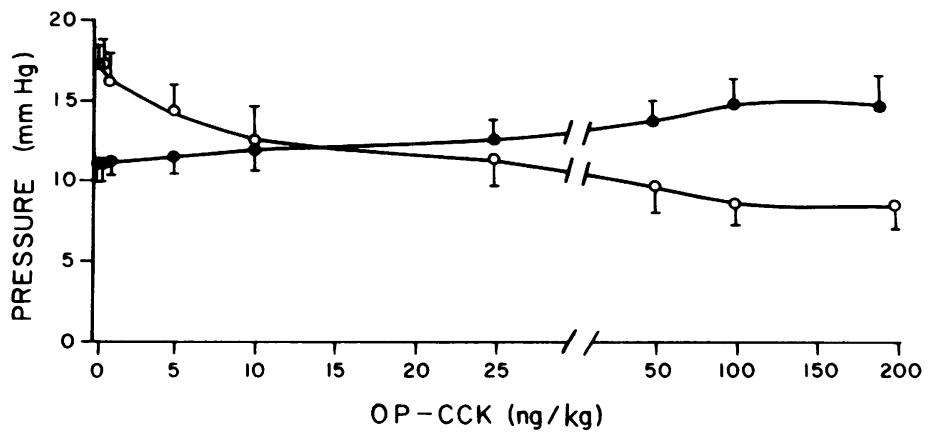

FIGURE 3 Dose-response studies of OP-CCK $(0.5-200 \mathrm{ng} / \mathrm{kg})$ on tonic gallbladder $(O)$ and SO $(O)$ pressures. Values are means $\pm \mathrm{SE}$ of eight experiments.

gallbladder. It reduced the gallbladder pressure increment to $0.9 \pm 0.2 \mathrm{~mm} \mathrm{Hg}(P<0.01)$. The gallbladder, however, did not respond to nicotine at all after the administration of hexamethonium $(P<0.01)$.

Effect of adrenergic blocking agents. Maximal doses of propranolol or phentolamine did not significantly affect tonic gallbladder pressures (Table I). Basal pressures were $7.5 \pm 1.4 \mathrm{~mm} \mathrm{Hg}$ and $7.9 \pm 1.3 \mathrm{~mm}$ $\mathrm{Hg}$ after propranolol $(P<0.40)$. Likewise, after phentolamine, gallbladder pressures remained essentially unchanged from control pressures of $11.0 \pm 1.8$ to 11.7

TABLE I

Pharmacological Analysis of the Action of the Octapeptide of Cholecystokinin on Gallbladder Pressures

\begin{tabular}{|c|c|c|c|c|c|}
\hline & $n$ & $\begin{array}{c}\text { Basal } \\
\text { pressures }\end{array}$ & $P<*$ & $\Delta$ pressures & $P<*$ \\
\hline & & $m m \mathrm{Hg}$ & & $m m \mathrm{Hg}$ & \\
\hline Control & 7 & $7.5 \pm 1.4 \ddagger$ & 040 & $1.2 \pm 0.2 \S$ & 04 \\
\hline Propranolol & 7 & $7.9 \pm 1.3$ & 0.40 & $1.3 \pm 0.5$ & 0.40 \\
\hline Control & 6 & $11.0 \pm 1.8$ & 050 & $2.3 \pm 0.5$ & 050 \\
\hline Phentolamine & b & $11.7 \pm 1.6$ & 0.50 & $2.1 \pm 0.7$ & 0.50 \\
\hline Control & 11 & $10.0 \pm 0.5$ & 0009 & $2.5 \pm 0.4$ & 009 \\
\hline TTX & 11 & $8.2 \pm 0.7$ & 0.002 & $1.1 \pm 0.3$ & \\
\hline Control & & $9.1 \pm 0.9$ & & $2.3 \pm 0.4$ & \\
\hline Atropine & 11 & $8.3 \pm 1.0$ & 0.20 & $1.9 \pm 0.3$ & 0.60 \\
\hline Control & 6 & $9.9 \pm 1.2$ & 0001 & $1.7 \pm 0.2$ & 05 \\
\hline $\begin{array}{l}\text { Hexameth- } \\
\text { onium }\end{array}$ & 0 & $8.7 \pm 1.2$ & 0.001 & $1.4 \pm 0.2$ & .05 \\
\hline Control & 13 & $9.7 \pm 0.9$ & 0.001 & $2.5 \pm 0.5$ & 0.01 \\
\hline $\begin{array}{l}\text { Atropine and } \\
\text { Hexameth- } \\
\text { onium }\end{array}$ & 13 & $6.9 \pm 0.5$ & 0.001 & $1.1 \pm 0.2$ & 0.01 \\
\hline
\end{tabular}

$n$ represents number of experiments.

* $P$ values determined by the paired Student's $t$ test.

f Values represent the mean $\pm \mathrm{SE}$ of basal gallbladder pressures.

$\S$ Values indicate mean $\pm \mathrm{SE}$ of pressure changes induced by CCK (100 ng/kg). $\pm 1.6 \mathrm{~mm} \mathrm{Hg}(P<0.50)$. Furthermore, neither propranolol nor phentolamine, in doses that blocked maximal doses of isoproterenol or phenylephrine, respectively, antagonized the effect of OP-CCK either on gallbladder pressures (Table I) or on tonic and phasic SO pressures $(P>0.20$, Table II).

Effect of TTX. TTX, in doses sufficient to block vagal stimulation of the gallbladder $(12 \mu \mathrm{g} / \mathrm{kg})$, decreased basal gallbladder pressures from $10.0 \pm 0.5$ to $8.2 \pm 0.7 \mathrm{~mm} \mathrm{Hg}(P<0.002)$. The same dose of TTX also partially blocked the effect of a maximal dose of OPCCK on the gallbladder (Table I). The gallbladder contraction in response to OP-CCK decreased from $2.5 \pm 0.4 \mathrm{~mm} \mathrm{Hg}$ in the control state to $1.1 \pm 0.3 \mathrm{~mm} \mathrm{Hg}$ after addition of TTX $(P<0.02)$. To further examine the TTX effect on the gallbladder response to OP-CCK, we performed dose-response studies using 1 to 200 $\mathrm{ng} / \mathrm{kg}$. Fig. 5 shows that TTX $(36 \mu \mathrm{g} / \mathrm{kg})$ partially

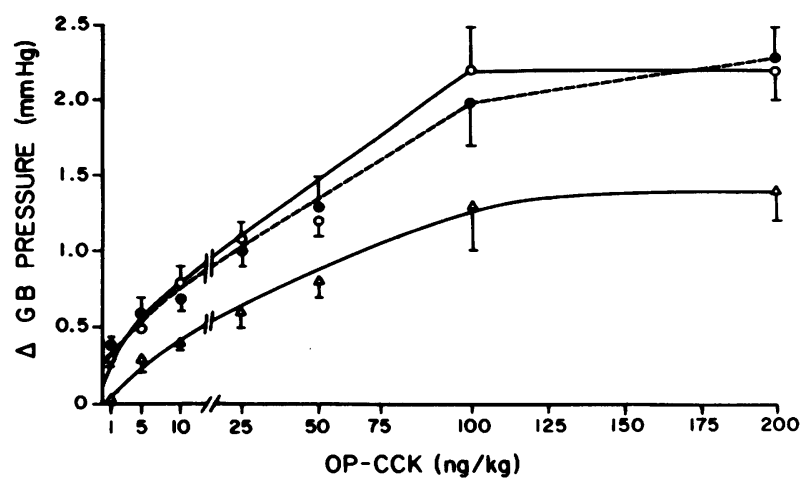

Figure 4 Effect of atropine alone and of a combination of atropine and hexamethonium on the gallbladder response to doses of OP-CCK (1-200 ng/kg). Values are means \pm SE of six experiments. Atropine did not affect the gallbladder response to OP-CCK $(P>0.05)$. Atropine and hexamethonium partially blocked the gallbladder contraction induced by all doses of OP-CCK $(P<0.01)$. The symbol for control is $(O)$, for atropine is $(\Theta)$, and for atropine + hexamethonium is $(\triangle)$. 
TABLE II

Effect of Pharmacological Antagonists on the OP-CCK-induced Relaxation of the SO

\begin{tabular}{|c|c|c|c|c|c|c|c|}
\hline & \multirow[b]{2}{*}{$n$} & \multicolumn{3}{|c|}{ Tonic contractions } & \multicolumn{3}{|c|}{ Phasic contractions } \\
\hline & & Basal & OP-CCK & $P<*$ & Basal & OP-CCK & $P<*$ \\
\hline Control & 6 & $21.9 \pm 2.4 \ddagger$ & $13.9 \pm 1.7 \ddagger$ & 90 & $14.2 \pm 2.5 \ddagger$ & 0 & \\
\hline Phentolamine & 6 & $17.5 \pm 1.3$ & $10.5 \pm 1.7$ & 0.20 & $11.9 \pm 1.0$ & 0 & 0.90 \\
\hline Control & & $17.3 \pm 1.3$ & $10.0 \pm 0.9$ & & $19.1 \pm 1.8$ & 0 & \\
\hline Propranolol & 5 & $17.0 \pm 1.4$ & $9.9 \pm 0.7$ & 0.60 & $18.0 \pm 1.2$ & 0 & 0.90 \\
\hline Control & & $17.5 \pm 0.5$ & $11.2 \pm 0.3$ & & $21.3 \pm 2.0$ & 0 & 00 \\
\hline Atropine and Hexamethonium & 7 & $17.0 \pm 0.4$ & $10.7 \pm 0.2$ & 0.20 & $16.8 \pm 1.7$ & 0 & 0.90 \\
\hline
\end{tabular}

$n$ represents the number of experiments.

* $P$ values are the result of the paired Student's $t$ test.

$\$$ Values are the mean $\pm \mathrm{SE}$.

blocked the effect of this neuropeptide at all doses studied $(P<0.05)$. This dose of TTX, however, did not affect the gallbladder response to a maximal dose of bethanechol $(40 \mu \mathrm{g} / \mathrm{kg})$. Before TTX, the gallbladder responded to bethanechol with a pressure increment of $2.0 \pm 0.6 \mathrm{~mm} \mathrm{Hg}$; after treatment it was $1.8 \pm 0.3 \mathrm{~mm} \mathrm{Hg}$ in six experiments $(P<0.50)$.

Intravenous infusion of TTX caused an immediate and sustained increase in tonic SO pressures as well as in the frequency of phasic contractions (Fig. 6). The dose $(12 \mu \mathrm{g} / \mathrm{kg})$ that blocked vagally induced relaxation of the SO was not large enough to antagonize the CCK effect. Doses of up to $36 \mu \mathrm{g} / \mathrm{kg}$ of TTX were needed to block the OP-CCK-induced relaxation, and at that point OP-CCK $(100 \mathrm{ng} / \mathrm{kg})$ caused contraction of the SO (Fig. 7). The SO, however, was still able to relax in response to stimuli, such as isoproterenol, that act directly on smooth muscle (Fig. 8). To further examine the nature of the TTX antagonism to OP-CCK in the SO, we performed a dose-response study with OP-CCK from 1 to $200 \mathrm{ng} / \mathrm{kg}$ before and after TTX $(36 \mu \mathrm{g} / \mathrm{kg})$. Before TTX, the SO relaxed in response to all doses of OP-CCK (1-200 ng/kg), whereas after TTX, it responded with contraction to doses of 5 to 200 ng/kg (Fig. 9).

Effect of isoproterenol on the gallbladder response to OP-CCK. Because the gallbladder response to OPCCK was partially blocked by TTX and by combined hexamethonium and atropine, antagonists that also reduce basal gallbladder pressures, we examined the possibility that the reduced gallbladder response to OP-CCK was a result of lower basal pressures. We therefore performed an experiment in which basal gallbladder pressures were reduced by the same magnitude observed after the addition of these pharmacological antagonists. This was accomplished by using a constant isoproterenol infusion $(2 \mu \mathrm{g} / \mathrm{kg}$ per min) that reduced pressures by $20-30 \%$. The OP-CCK doseresponse curves before and during the infusion of isoproterenol were not significantly $\operatorname{different}(P>0.05$, Fig. 10).

\section{DISCUSSION}

The results of this study indicate that both CCK and OPCCK cause simultaneous gallbladder contraction and SO relaxation. The minimal and maximal doses of both CCK that caused gallbladder contraction and SO relaxation were similar. However, the $D_{50}$ of CCK and OP-CCK was lower for the SO than for the gallbladder. Since the effect of CCK on the gallbladder is considered to be one of the physiological actions of this gastrointestinal hormone (6), these findings suggest that the CCK-induced relaxation of the SO may also be

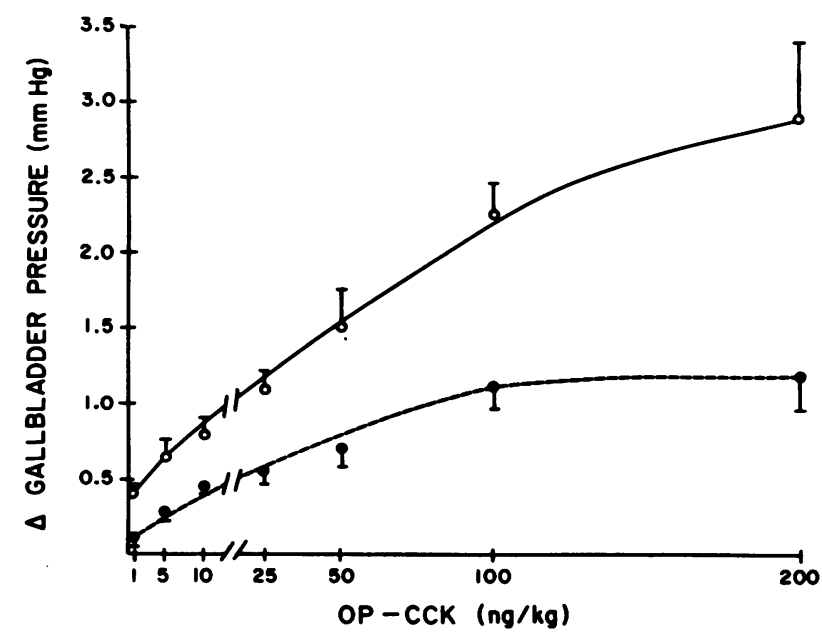

Figure 5 Effect of doses of OP-CCK (1-200 $\mathrm{ng} / \mathrm{kg})$ on the gallbladder before and after TTX $(36 \mu \mathrm{g} / \mathrm{kg})$. Values are means $\pm S E$ of six experiments. TTX caused partial antagonism to all doses of OP-CCK which included gallbladder contraction $(P<0.05)$. The symbol for TTX is $(O)$ and the symbol for the control is $(O)$. 


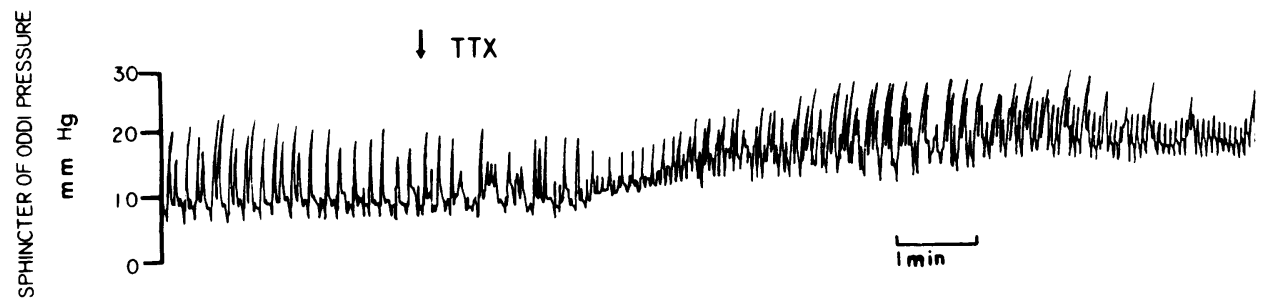

FIGURE 6 Tracing illustrates the rise in tonic pressures and frequency of phasic contractions of the SO during an intravenous infusion of $12 \mu \mathrm{g} / \mathrm{kg}$ of TTX. Arrow indicates the onset of TTX infusion.

physiological. Further studies, however, are needed to demonstrate this assumption and meet the criteria for proof of the physiological action of gastrointestinal hormones (15).

Pharmacological analysis of the mechanism of the CCK action indicates that there are two excitatory receptors in the gallbladder. CCK appears to cause contraction by direct action on the gallbladder muscle, because it was not inhibited completely by any neural antagonist used, including TTX. Cholinergic antagonists, such as hexamethonium alone or in combination with atropine, caused a partial block of the gallbladder response to CCK. Similar results were obtained when the gallbladder was denervated with TTX. These observations suggest a second receptor for CCK at the postganglionic cholinergic neurons. The failure of atropine alone to antagonize the CCK action, however, would indicate the existence of a nicotinic as well as muscarinic receptor for acetylcholine at the gallbladder muscle (16). Alternatively, the failure of atropine alone could suggest the presence of a cholinergic pathway with synaptic transmission to an excitatory noncholinergic, nonadrenergic neuron. These hypotheses are supported by our studies with nicotine, which caused gallbladder contraction that was partially antagonized by atropine. Complete block of the nicotine action requires the specific nicotinic blocker, hexamethonium. These findings also agree with our previous studies on the nature of the excitatory vagal fibers innervating the feline gallbladder (13). We found that gallbladder contraction, resulting from electrical stimulation of the peripheral or central ends of the cervical vagus, is not affected by atropine alone but is antagonized entirely by atropine and hexamethonium. Our present findings are also consistent with other studies that have demonstrated CCK receptors at the intramural cholinergic neurons in the guinea pig ileum and antrum $(17,18)$. Those studies showed that CCK can stimulate the release of acetylcholine in the ileum (17). In contrast, in vitro experiments have shown an exclusive CCK direct muscle action on the guinea pig gallbladder that was not impaired by atropine or even
TTX (4). In the in vitro studies, however, no attempt was made to determine whether the intrinsic cholinergic innervation of the gallbladder was functionally intact. Neurons are more sensitive to hypoxia than smooth muscle cells, and it is thus possible that these in vitro studies have dealt with almost pure muscle preparations (19). Alternatively, these dissimilarities could be the result of species differences.

The relaxation of the SO induced by CCK is not antagonized by adrenergic or cholinergic blocking agents. These findings agree with previous studies that failed to demonstrate any cholinergic or adrenergic antagonism to the CCK inhibition of the $\mathrm{SO}(11,12,20)$. We concluded that the CCK action was a direct hormonal effect on the SO circular muscle. Cholinergic and adrenergic antagonists do not entirely denervate the SO, however, and TTX treatment was necessary. These results would suggest that CCK stimulates intramural, noncholinergic, nonadrenergic inhibitory neurons. As for the feline lower esophageal sphincter (LES) (21), the dose of TTX needed to block CCK action on the SO was $36 \mu \mathrm{g} / \mathrm{kg}$, a dose greater than the one needed to block the SO response to vagal stimulation.

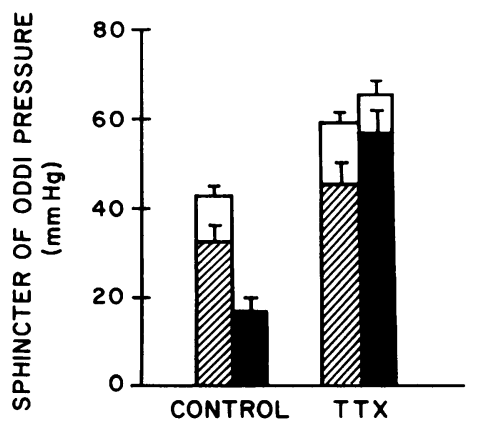

FIGURE 7 Effect of a maximal dose of OP-CCK $(100 \mathrm{ng} / \mathrm{kg})$ on the SO before and after TTX (36 $\mu \mathrm{g} / \mathrm{kg}$ ) (which causes complete denervation). Values are means $\pm S E$ of seven experiments. TTX blocked the inhibition of SO tonic $(\because)$ and phasic $(\square)$ contractions induced by OP-CCK $(\square)(P<0.001)$. 

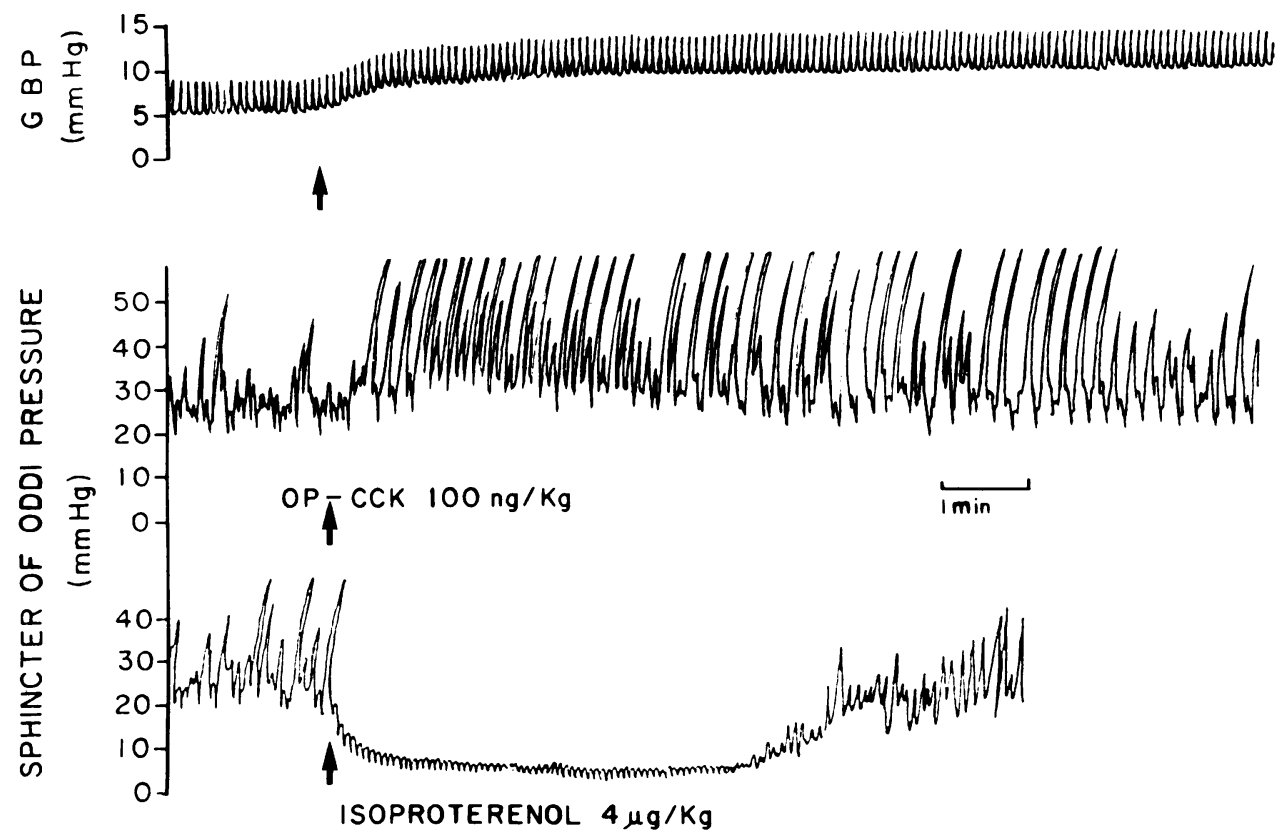

FIGURE 8 Tracing illustrates the effect of OP-CCK $(100 \mathrm{ng} / \mathrm{kg})$ after TTX on gallbladder pressures (upper panel) and on SO (middle panel) tonic and phasic contractions. It also shows the effect of isoproterenol $(4 \mu \mathrm{g} / \mathrm{kg}$ ) on SO pressures after TTX (lower panel). Arrows indicate the timing of the administration of the drugs.

This inhibitory innervation appears to play a substantial role in regulating tonic and phasic contractions of the SO circular muscle. TTX, which blocks the innervation selectively (22), caused a marked and persistent increase in tonic pressures as well as in the frequency of spontaneous phasic contractions of the

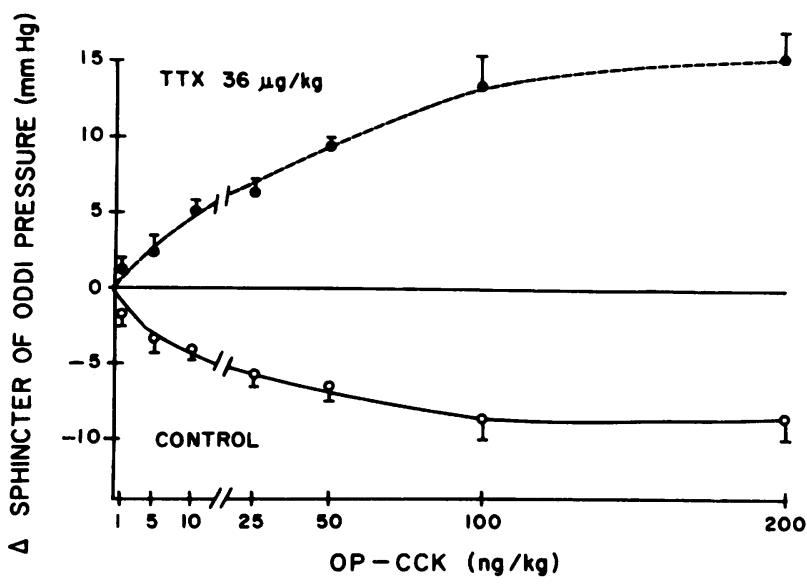

Figure 9 Effect of doses of OP-CCK $(1-200 \mathrm{ng} / \mathrm{kg})$ on SO tonic pressures before and after $36 \mu \mathrm{g} / \mathrm{kg}$ of TTX $(P<0.04)$. Values are means $\pm S E$ of four experiments. Whereas before treatment, OP-CCK caused relaxation of the SO, after TTX it caused SO contraction.
SO. Similar increases have been demonstrated in the opossum LES (23) but not in the feline LES (21). Furthermore, these intramural inhibitory neurons of the SO were more sensitive to this hormone than those of the LES. The $\mathrm{D}_{50}$ of OP-CCK required to inhibit $\mathrm{SO}$ pressures was $6 \mathrm{ng} / \mathrm{kg}$, compared with $100 \mathrm{ng} / \mathrm{kg}$ needed to attain a half-maximal response of the LES (21). The existence of these intramural non-cholinergic, non-adrenergic neurons in the $\mathrm{SO}$ is further supported by the finding that nicotine causes $\mathrm{SO}$ relaxation which is blocked by TTX. ${ }^{2}$

Recent studies have shown that the net effect of a gastrointestinal hormone or a pharmacological agent is the result of the algebraic sum of the actions of the stimulated receptors at the neuromuscular structure under study $(21,24)$. In the SO, the net CCK effect is a drop in pressure, indicating the predominance of inhibitory receptors. After complete SO denervation with TTX, a second CCK receptor is unmasked that mediates $\mathrm{SO}$ contraction, suggesting a direct action on its circular muscle. This second CCK action may be related to the presence of a terminal tetrapeptide molecule shared with gastrin.

In conclusion, these studies indicate the existence of four types of receptors for CCK in the biliary tree. The

${ }^{2}$ Behar, J. Unpublished observations. 


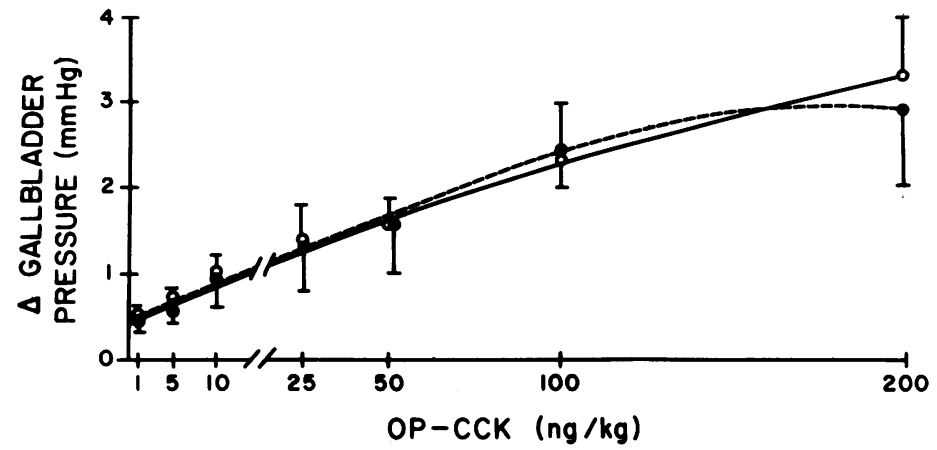

Figure 10 Effect of a continuous infusion of isoproterenol ( $2 \mu \mathrm{g} / \mathrm{kg}$ per $\mathrm{min})$ on the gallbladder response to increasing doses of OP-CCK $(1-200 \mathrm{ng} / \mathrm{kg})$. Values are means $\pm \mathrm{SE}$ of five experiments. Gallbladder pressure increment $(\Delta)$ in response to OP-CCK was not affected by a $30 \%$ reduction in its basal pressures $(P>0.05)$ during the isoproterenol infusion $(\Theta)$. The symbol for control is $(O)$.

gallbladder has two excitatory receptors, one at the muscle, and the other, most likely, at the intramural postganglionic cholinergic neurons. The SO also has two receptors: one inhibitory, most likely present at the intramural, inhibitory, noncholinergic, nonadrenergic, postganglionic neurons; the other excitatory, present at the circular muscle of the SO. The presence after denervation with TTX of four different receptors for CCK in the biliary tree creates an interesting experimental model. This experimental model may explain certain forms of postprandial right-upperquadrant pain attributed to one of the poorly defined syndromes of biliary dyskinesia $(25,26)$. Under these pathophysiological conditions, with absence of intramural ganglion cells, release of CCK by its physiological stimuli could cause simultaneous contractions in both gallbladder and SO, resulting in marked increase in intraductal pressures, and possibly in pain. Obviously, further studies are necessary to establish whether the functional post-prandial upper abdominal pain of some patients can be explained on the basis of this proposed hypothesis.

\section{ACKNOWLEDGMENTS}

The authors are grateful to Carol Marin and Susan Field for their technical assistance, to Lorie Klemer for her secretarial assistance, and to Michael Lipsky for the preparation of this manuscript.

OP-CCK was a gift from the Squibb Institute for Medical Research.

\section{REFERENCES}

1. Ivy, A. C., and E. Oldberg. 1928. A hormone mechanism for gallbladder contraction and evacuation. Am. J. Physiol. 86: $599-613$.

2. Ivy, A. C., G. E. Drewyer, and B. H. Orndoff. 1930. The effect of cholecystokinin on the human gallbladder. Endocrinology. 14: 343-348.
3. Lin, R. M. 1971. Hepatic, cholecystokinetic, and choledochal actions of cholecystokinin, secretin, caerulein, and gastrin-like peptides. Proc. Int. Congr. Physiol. Sci. 9: 1877.

4. Yau, W. M., G. M. Makhlouf, L. E. Edwards, and J. T. Farrar. 1973. Mode of action of cholecystokinin and related peptides on gallbladder muscle. Gastroenterology. 65: 451-456.

5. Amer, M. S. 1972. Studies with cholecystokinin in vitro. III. Mechanisms of the effect on the isolated rabbit gallbladder strips.J.Pharmacol. Exp. Ther. 183: 527-534.

6. Grossman, M. I. 1977. Physiological effects of gastrointestinal hormones. Fed. Proc. 36: 1930-1932.

7. Sandblom, P., W. L. Voegtlin, and A. C. Ivy. 1935. The effect of cholecystokinin on the choledochoduodenal mechanism (sphincter of Oddi). Am. J. Physiol. 93: $175-180$.

8. Hong, S. S., D. F. Magee, and F. Crewdson. 1956. The physiologic regulation of gallbladder evacuation. Gastroenterology. 30: 625-630.

9. Crema, A., G. Benzi, and F. Berte. 1962. The action of some natural substances on the terminal portion of the common bile duct isolated "in toto." Arch. Int. Pharmacodyn. 77: 307-317.

10. Sarles, J. C., J. M. Bidart, and M. A. Devaux. 1976. Action of cholecystokinin and caerulein on the rabbit sphincter of Oddi. Digestion. 14: 415-423.

11. Hedner, P., and G. Rorsman. 1969. On the mechanism of action for the effect of cholecystokinin on the choledochoduodenal junction in the cat. Acta. Physiol. Scand. 76: 248-254.

12. Persson, C. G. A., and M. Ekman. 1972. Effect of morphine, CCK, and sympathomimetics on the sphincter of Oddi and intestinal pressure in the cat duodenum. Scand. J. Gastroenterol. 7: 345-351.

13. Behar, J., and P. Biancani. 1980. Neural control of the feline gallbladder. In Gastrointestinal Motility. J. Christensen, editor. Raven Press, New York. 97-110.

14. Watts, J. M., and J. E. Dunphy. 1966. The role of the common bile duct in biliary dynamics. Surg. Gynecol. Obstet. 122: 1207-1218.

15. Debas, H. T., O. Farooq, and M. I. Grossman. 1975. Inhibition of gastric emptying is a physiological action of cholecystokinin. Gastroenterology. 68: 1211-1217.

16. Daniel, E. E. 1968. Pharmacology of the gastrointestinal tract. In Handbook of Physiology. VI. Alimentary Canal. 
C. F. Code, editor. American Journal of the Physiological Society, Washington, D. C. 4: 2267-2324.

17. Vizi, S. E., G. Bertaccini, M. Impicciatore, and J. Knoll. 1973. Evidence that acetylcholine released by gastrin and related polypeptides contributes to their effect on gastrointestinall motility. Gastroenterology. 64: 268-277.

18. Gerner, T., and J. F. W. Haffner. 1977. The role of local cholinergic pathways in the motor response to cholecystokinin and gastrin in isolated guinea-pig fundus and antrum. Scand. J. Gastroenterol. 12: 751-757.

19. Szurszewski, J. H. 1966. The relationship of the myenteric plexus to the electrical and mechanical activity of the small intestine in unanesthetized animals. (Ph.D. Thesis), Urbana, Illinois. University of Illinois.

20. Andersson, K. E., R. Andersson, and P. Hedner. 1972. Effect of cholecystokinin on the level of cyclic AMP and on mechanical activity in the isolated sphincter of Oddi. Life Sci. 11: 723-732.

21. Behar, J., and P. Biancani. 1977. Effect of cholecystokinin- octapeptide on the lower esophageal sphincter. Gastroenterology. 73: 57-61.

22. Kao, C. Y. 1972. Pharmacology of tetrodotoxin and saxitoxin. Fed. Proc. 31: 1117-1123.

23. Goyal, R. K., and S. Rattan. 1976. Genesis of basal sphincter pressure: effect of tetrodotoxin on lower esophageal sphincter pressure in opossum in vivo. Gastroenterology. 71: 62-67.

24. Rattan, S., and R. K. Goyal. 1977. Effects of 5-hydroxytryptamine on the lower esophageal sphincter in vivo. $J$. Clin. Invest. 59: 125-133.

25. Ivy, A. C. 1972. Biliary tract dyskinesia produced in part by cholecystokinin plus secretin: what was the mechanism? In Gastrointestinal Hormones, International Symposium at Erlanger. E. L. Demling, editor. Georg Thieme Verlag K. G., Stuttgart. 56-58.

26. Dahl-Iversen, E., A. H. Sorensen, and E. Westergaard. 1958. Pressure measurement in the biliary tract in patients after cholecystectolithomy and in patients with dyskinesia. Acta Chir. Scand. 114: 181-190. 